\title{
An investigation of the moisture content in the walls of a straw-bale building
}

\author{
Steve Goodhew ${ }^{\star 1}$ a Richard Griffiths $^{\mathrm{b}}$ and Tom Woolley ${ }^{\mathrm{c}}$ \\ ${ }^{a}$ University of Plymouth, School of Engineering, Devon, UK. \\ ${ }^{\mathrm{b}}$ University of Plymouth, School of Architecture, Devon, UK \\ ${ }^{\text {c }}$ Queens University Belfast, UK
}

\begin{abstract}
This paper examines the use and accuracy of a moisture probe used in the walls of a straw-bale building. The performance of the moisture probe is assessed against laboratory based measurements. The measurements from a number of moisture probes placed in the walls of a case study straw-bale building over a two-year period are presented. The moisture content measurements from the building are discussed in the light of laboratory findings and the condition of the straw in the lower part of the most exposed wall. Potential influences upon the readings obtained from the moisture probes along with possible alternative assessment methods are discussed.
\end{abstract}

\section{Keywords}

Straw-bale, in-situ moisture measurement, thermal properties, sustainable building techniques,

\section{Introduction}

Buildings made wholly or partly from straw have been constructed in the UK using techniques similar to contemporary designs in the Northern United States of America. The resurgence of this building technique has been prompted by a range of issues but most stem from the inherent sustainability of the structure of such buildings. In this sense sustainability is defined not only in terms of energy efficiency but also the use of local and renewable materials. Such materials reduce carbon emissions and energy used in transport and manufacturing. Also from a life cycle point of view natural materials can degrade at the end of life and do not cause pollution or hazards. The UK department of Trade and Industry has recently recognised this by funding a study into construction materials from crops. (CIRIA RP680 [1] )

The straw-bales offer good insulation values, according to Christian et al [2]. The measured steady-state R-value, (thermal resistance) for a straw-bale wall, built according to the Tucson, Arizona, structural code, was $2.8 \mathrm{~m}^{2} \mathrm{~K} / \mathrm{W}$, equivalent to a thermal transmission value of $0.35 \mathrm{~W} / \mathrm{m}^{2} \mathrm{~K}$. This is complemented by other factors such as straw is normally a waste product and the ease of disposal of any straw after its use as a building material.

However, straw-bale buildings, by their very nature are organic and are liable to suffer degeneration due to certain combinations of moisture and temperature. It has been suggested that the ideal moisture content of a straw-bale wall is $14 \%$, as this is below the level that is believed to allow biological activity to begin (Steen et al [3]). This is echoed by Still 'At 20\% moisture content most organic material starts to degrade such as grains, wood and straw.' (Still [4]). Degradation of rice straw has been found to be

\footnotetext{
${ }^{* 1}$ Corresponding author. Fax:+44 (0) 1752 232638, E-mail address: sgoodhew@plymoth.ac.uk
} 
reliant on a function of moisture content and humidity of stored bales, (Summers et al,[5]). However, moisture content and temperature are only part of a range of factors influence the degradation that will occur within straw-bale walls. These wider factors, include the building design and detailing used, but also rely heavily upon the buildings siting, orientation and the regional climate of the site. It was therefore proposed that a moisture study should be carried out to establish the moisture content of a straw-bale wall in a particular geographical region.

Relative humidity and temperature measurements have been taken from the upper, middle and lower sections of a California winery built from straw-bales, (Straube and Schumacher [6]). The measurements were taken using combined relative humidity and temperature sensors. The results from these measurements, although comprehensive, focused on the relative humidity in the straw-bale walls and did not relate these figures to the actual moisture content of the straw.

The most common method used to measure the moisture content of straw-bale wall is the wood-disc sensor, (Fugler [7]). This is mainly because they are cheap, easy to read and are viewed as being reasonably accurate. Fugler's paper compares several series of laboratory-based moisture studies in an attempt to calibrate the most commonly used design. The paper's analysis of field studies carried out upon three Quebec straw-bale houses in 1997 concluded that most straw-bales were usually dry enough to avoid rot, but also stated that there '.......are not enough monitored houses to make conclusions'.

This study will investigate the performance of a wood-disc moisture probe using laboratory measurements and presents the results from a number of probes placed in the external straw-bale walls of a case study building.

\section{The Wood-disc Moisture Probe}

The wood disc moisture probe chosen is based upon the work carried out by Canada Mortgage and Housing Corporation and is advocated by Gonzalez of the University of British Columbia (Gonzalez [8]) and Woolley of Queens University Belfast, (Woolly \& Kimmins [9])

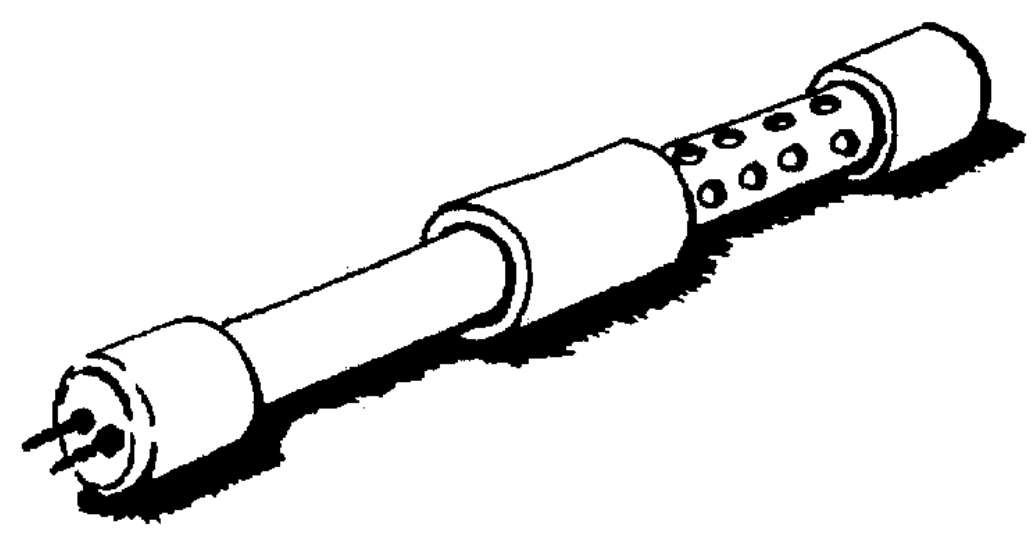

Figure 1 illustrates a typical wood-disc moisture probe.

The wood disc moisture probes, of area $25 \mathrm{~mm}^{2}$ were constructed of wood 5-mm thick. The block is drilled in 2 places to make holes $5 \mathrm{~mm}$ apart, although the exact distance is unimportant (Lacinski et al [10]). Two stainless steel screws are then inserted with a 
stripped end of a piece of wire wrapped around the head of each screw. The wooddisc is then placed at the end of a PVC tube with ventilation holes made around it. The tube can vary in length depending upon how deep into the wall it is being placed. The two wires are then run the length of the tube and left protruding out of the end. These will be outside the building, ready for readings to be taken. Readings are taken using a 'Protimeter' Wood Moisture Meter calibrated for wood. The moisture content of the wood-disc within the probe is influenced by the relative humidity of the bale via the vent holes in the PVC tube. In this way the moisture content of the bales may be assessed.

The reaction times and the operation of the probes at different temperatures is an issue. Fugler measured the response of several wood-disc moisture probes (as opposed to the discs used here, using two varieties of timber, Balsa and White Pine, and found that a time lag existed for any probe measuring Relative Humidity. However, when the wood-disc moisture probes were used to monitor straw-bale buildings, the slow reaction of the probes matched the slow reaction of the straw to the uptake of moisture. As part of the same measurements Fugler also investigated the wood-disc moisture probe's response at different temperatures. It was found that there may be some influence of temperature on response, but for the range of temperatures studied (13 C to about $28 \mathrm{C}$ ) the influence was small and difficult to determine. However, Fugler does state that for measurements in winter, in cold climates, a temperature correction would be necessary. This correction is further investigated within the calibration section of this paper.

A further concern maybe the electrical effects of the length of connecting wire used between the wood-disc and the connection with the electrical moisture meter. Lacinski investigated this aspect and found that using identical wood samples and wires that ranged in length from 3 to 21 metres, all the moisture readings were within $1 \%$ of each other. (Lacinski et al [10])

\section{Calibration of the wood-disc sensors}

An initial study to calibrate and assess the validity of measurements taken using the moisture probe was carried out in the laboratory. One bale of the straw, from the batch used in the case study building, was placed in an exterior storeroom with three wooddisc sensors placed inside the bale. Two pieces of timber, identical to those inside the sensors, were also placed in the bale. The relative humidity and temperature conditions around the bale were monitored. The bale was allowed a week to stabilise and then readings were taken twice weekly from the wood-disc sensors, the hygrometer and the thermometer. Further to this, straw samples were taken from the bale at the same time and (1) oven dried and (2) measured using a moisture balance to find the exact moisture content. The results of this calibration are shown in table 1.

The oven dried moisture content was calculated using:-

wet weight - dry weight dry weight

$\times 100=$ percentage Moisture Content, referred to as $\mathrm{mc} \%$.

To ensure that the readings that were being gathered from the wood disc probes gave a valid measurement of the moisture content of the straw-bale walls of the case study building, a laboratory calibration exercise was carried out. 


\section{Laboratory calibration.}

The laboratory calibration compared the results from a wood disc probe to a bare wood disc without outer sheath. Oven dried and moisture balance based measurements from samples of the straw around the probe were also compared to the wood-disc probe readings. The probe was placed in similar conditions to the positioning of the probe when placed in the walls of the case study building. The bale and probe were allowed to vary in moisture content and at regular intervals calibration measurements were taken. Ambient air temperatures and relative humidity were recorded using electronic hygrometers as part of the calibration process and this enabled further assessment of the conditions around the bale at the time the measurements were being taken.

Unsurprisingly the moisture in straw surrounding the wood disc was seen to vary according to the season and prevailing weather from all the measurement techniques.

\begin{tabular}{|c|c|c|c|}
\hline $\begin{array}{c}\text { Wood-disc sensor } \\
\text { average reading } \\
(\%\end{array}$ & $\begin{array}{c}\text { Wood-disc without } \\
\text { casing average } \\
\text { reading } \\
\text { moistureContent) } \\
\text { Content) }\end{array}$ & $\begin{array}{c}\text { Oven dried } \\
\text { samples average } \\
\text { moisture content } \\
\text { (\% moisture } \\
\text { Content })\end{array}$ & $\begin{array}{c}\text { Moisture Balance } \\
\text { average readings } \\
\text { (\% moisture } \\
\text { Content) }\end{array}$ \\
\hline 11 & 12 & 10 & 19 \\
\hline
\end{tabular}

Table 1 Showing the average readings of different methods of assessing the moisture content of the storeroom bale.

It can be clearly seen that oven drying represents the closest match to the moisture content readings from either the wood-disc sensors or the bare wood samples. If the oven drying method is assumed to be accurate, this gives a potential accuracy of the wood-disc sensors of $+/-1 \%$ upon the scale of a moisture meter. The slightly higher value of the bare wood-disc could be caused by the potentially faster response to moisture variances in the bale because of the lack of shielding of the enclosed sensors. The moisture balance results were considerably higher and were felt to be generally less reliable when used to ascertain the moisture content of organic or changeable samples.

The measurement of the ambient air temperatures and relative humidities around the straw-bale allowed the analysis of the affect of different temperatures. Changes in temperature in the air around the straw-bale used for calibration purposes did not appear to markedly alter the accuracy of the wood-disc sensors over the temperature ranges encountered in the study. However, it was found that an increase in temperature in the straw surrounding a wood-disc moisture probe did lead to a small increase in moisture content measurements.

\section{The case study building}

The in situ measurements were taken from a case study building situated on the north eastern edge of Dartmoor. The building was constructed approximately 5 years ago, has a timber frame with straw infill, and uninsulated roof. The straw-bale infill walls have a lime based render applied to them, both on the interior and exterior, with smaller areas of timber cladding. There are some areas of glazing, mostly concentrated in the north east corner, through some of the timber cladding, (see figure 2). The timber floor is suspended over the site at an average height of approximately $400 \mathrm{~mm}$. This feature of the design allows the placement of any wood-disc sensors into the base of the walls from the underside. The building is used for storage at present and has no heating. 


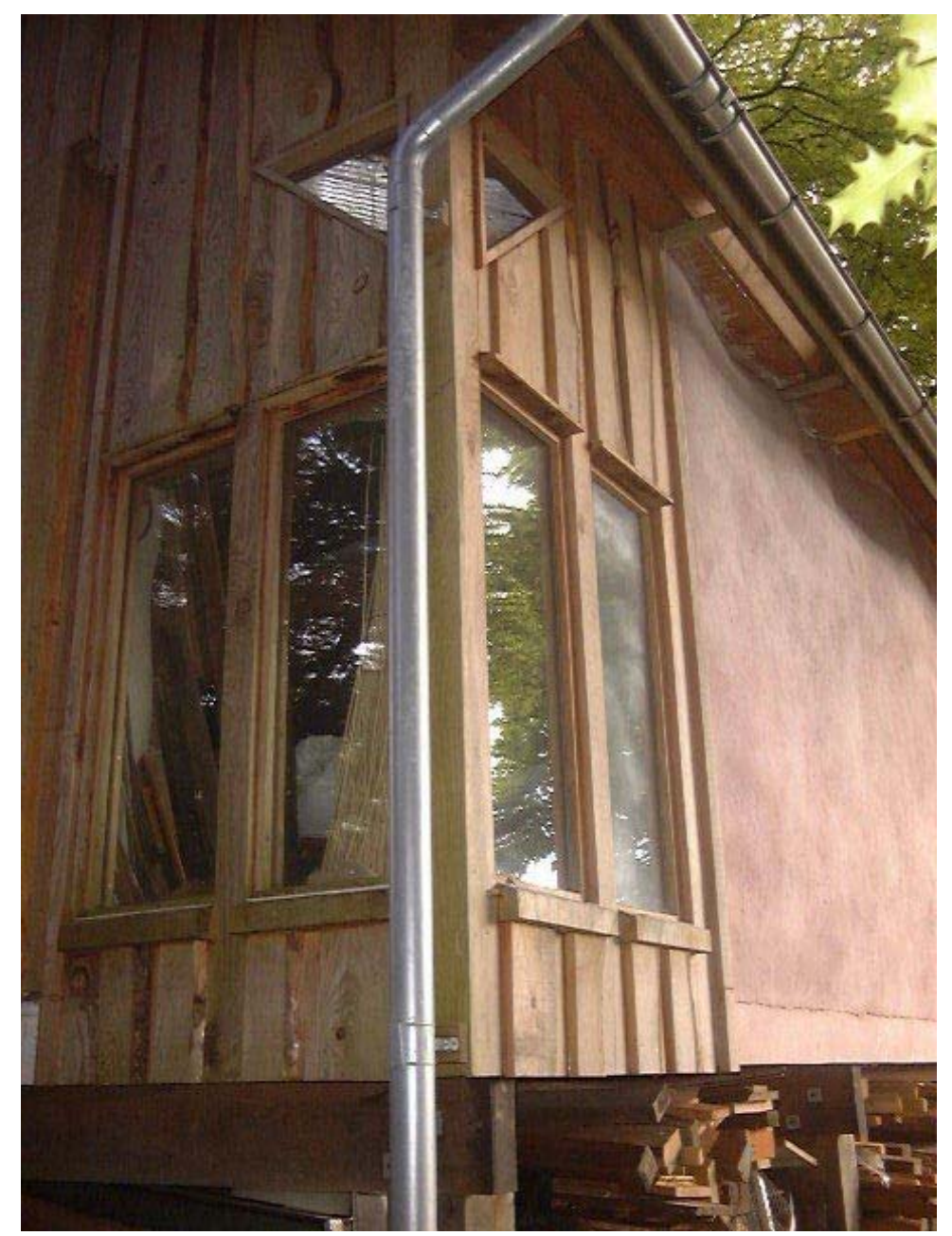

Figure 2, The south-east corner of the case study building.

Due to the many surrounding mature trees, mostly concentrated around the northern and eastern elevations, the environmental conditions around the building encourage an unusually high relative humidity. The moisture content within the walls of the building and in the relative humidity surrounding it, have been recorded since November 2000. Wood-disc probes were inserted into the walls after construction. Figure 3 shows a floor plan of the building with the location of the probes marked by letters $A$ to I,(probe ' $C$ ' stopped functioning soon after fitment and so readings are not included). Two hygrometers were also installed in the building, one on the inside and outside of the external walls on the building. 


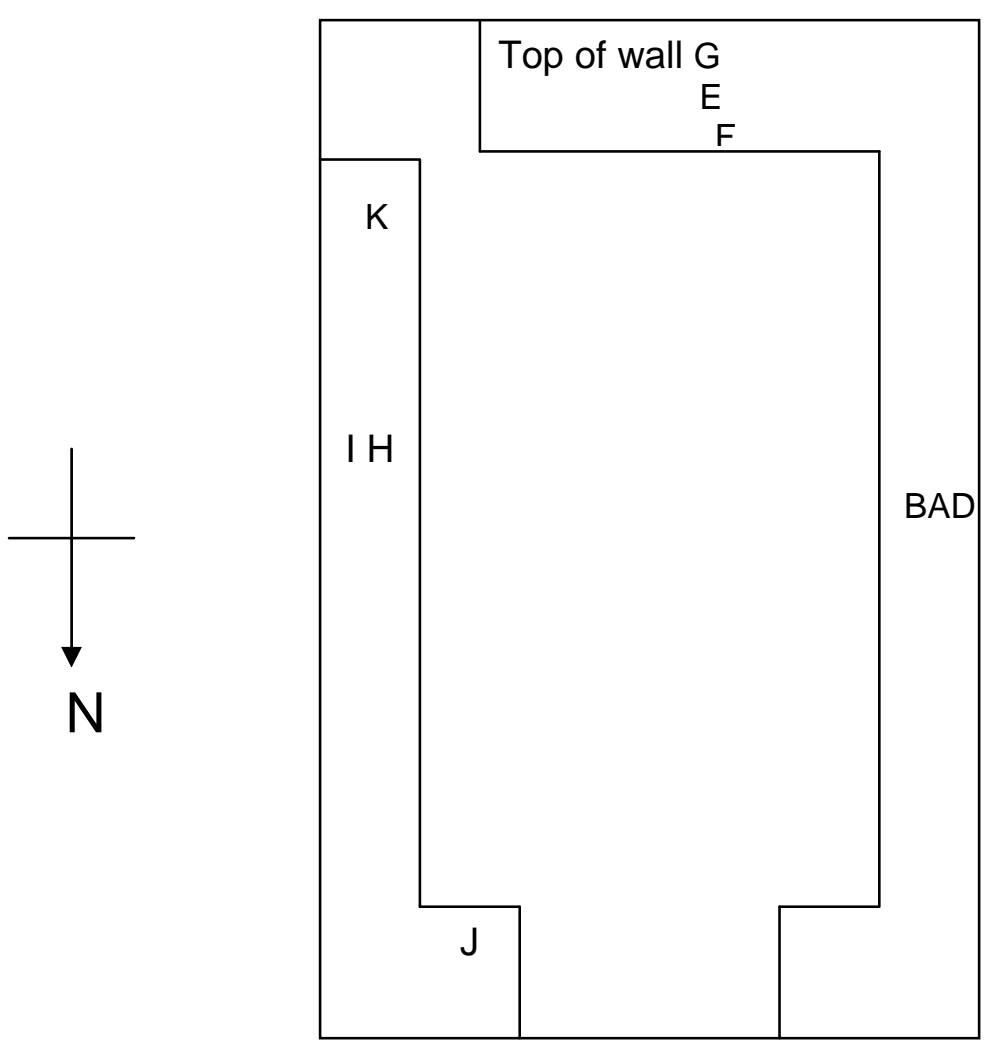

Figure 3, Case study building floor plan and wood-disc sensor and hygrometer locations.

\section{Results for the case-study building.}

The following results are from the wood disc sensors placed in the three orientations of straw-bale walls of the case study building. This information is supplemented by readings taken from rainfall and relative humidity meters placed in the inside and outside of the building. Table 2 indicates to the reader the locations of the probes and more exact locations can be seen in figure 3 .

$\begin{array}{cccccccc}\text { A } & \text { B } & \text { D } & \text { E } & F & \text { G } & \text { H } & \text { I } \\ \text { West } & \text { West } & \text { West } & \text { South } & \text { South } & \text { South } & \text { East } & \text { East } \\ \text { Wall } & \text { Wall } & \text { Wall } & \text { Wall } & \text { Wall } & \text { Wall } & \text { Wall } & \text { Wall } \\ \text { Bottom } & \text { Bottom } & \text { Bottom } & \text { Bottom } & \text { Bottom } & \text { Top } & \text { Bottom } & \text { Bottom } \\ \text { Middle } & \text { Inner } & \text { Outer } & \text { Outer } & \text { Inner } & \text { Middle } & \text { Inner } & \text { Outer }\end{array}$

Table 2 Locations of moisture probes 


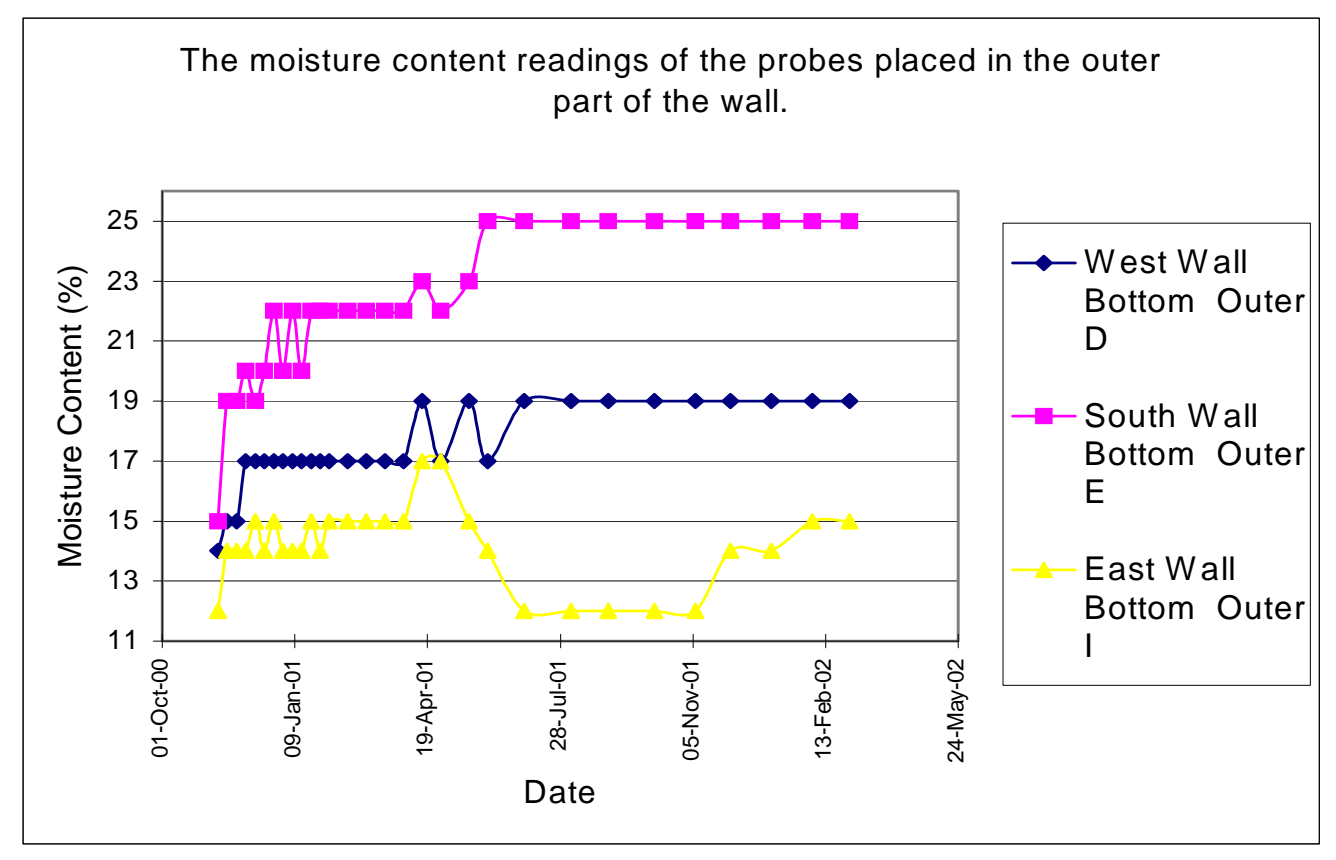

Figure 4, Moisture content of the outer section of the three main orientations of the straw-bale walls of the case study building.

As expected, the three outer probes, gave moisture readings that are influenced by the exposure at each wall. The south facing façade is most exposed and starts from a moisture content close to $15 \%$ and steadily rises to an equilibrium moisture content of $25 \%$. The west and east facing walls have initial moisture contents of $14 \%$ and $12 \%$ respectively. Both east and west walls moisture content are steady until the $19^{\text {th }}$ April 2002 , but then sharply increase. The moisture content of the east wall falls to $12 \%$ and then gradually rises, in contrast to the more steady moisture content of the west wall, remaining at $19 \%$.

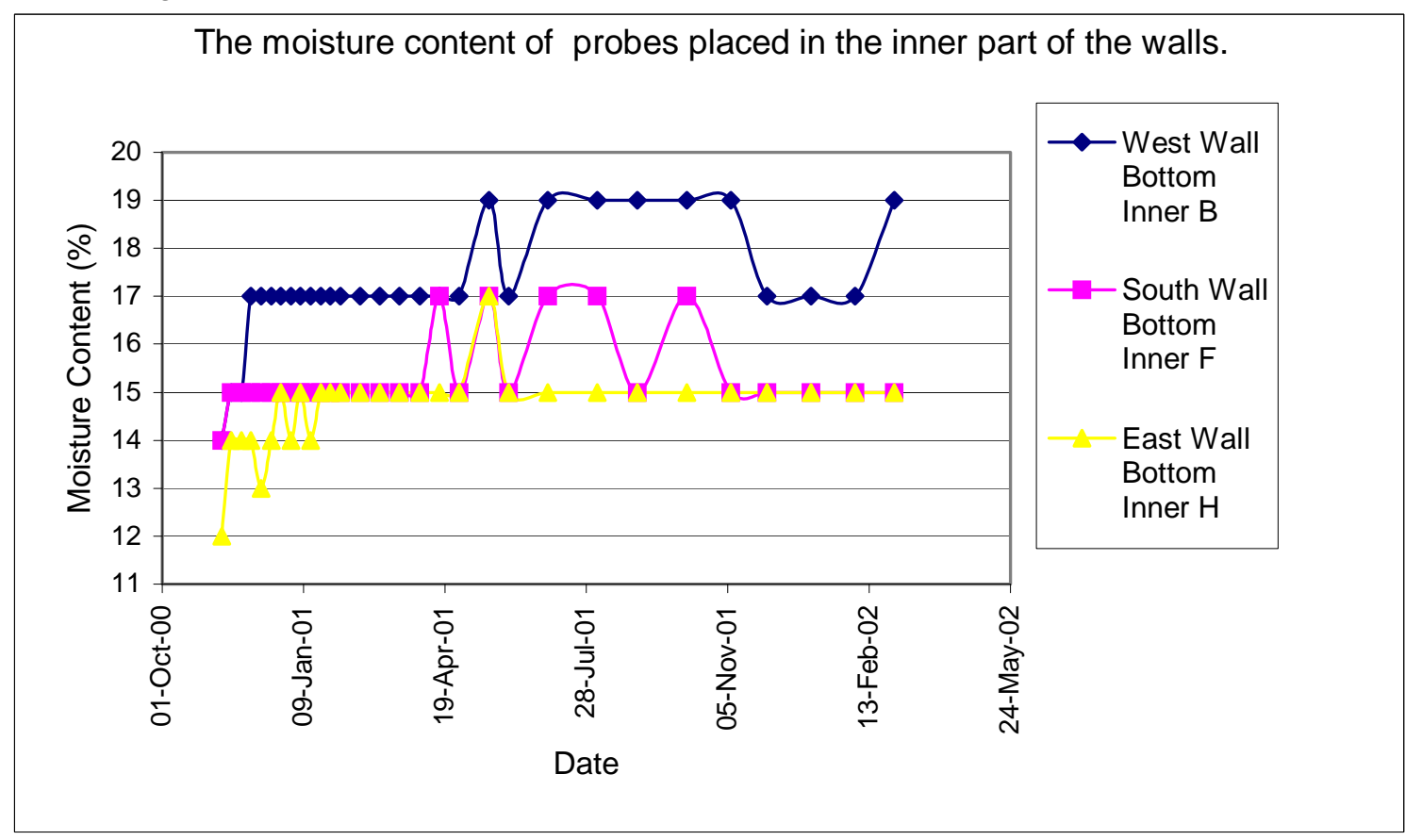

Figure 5, Moisture content of the inner section of the three main orientations of the straw-bale walls of the case study building. 
Unsurprisingly, figure 5 shows the inner wall probes record initial moisture readings similar to those recorded for the outer parts of the same wall. However, the south facing wall is drier than the west facing wall, reversing the trend shown by the outer probe readings.

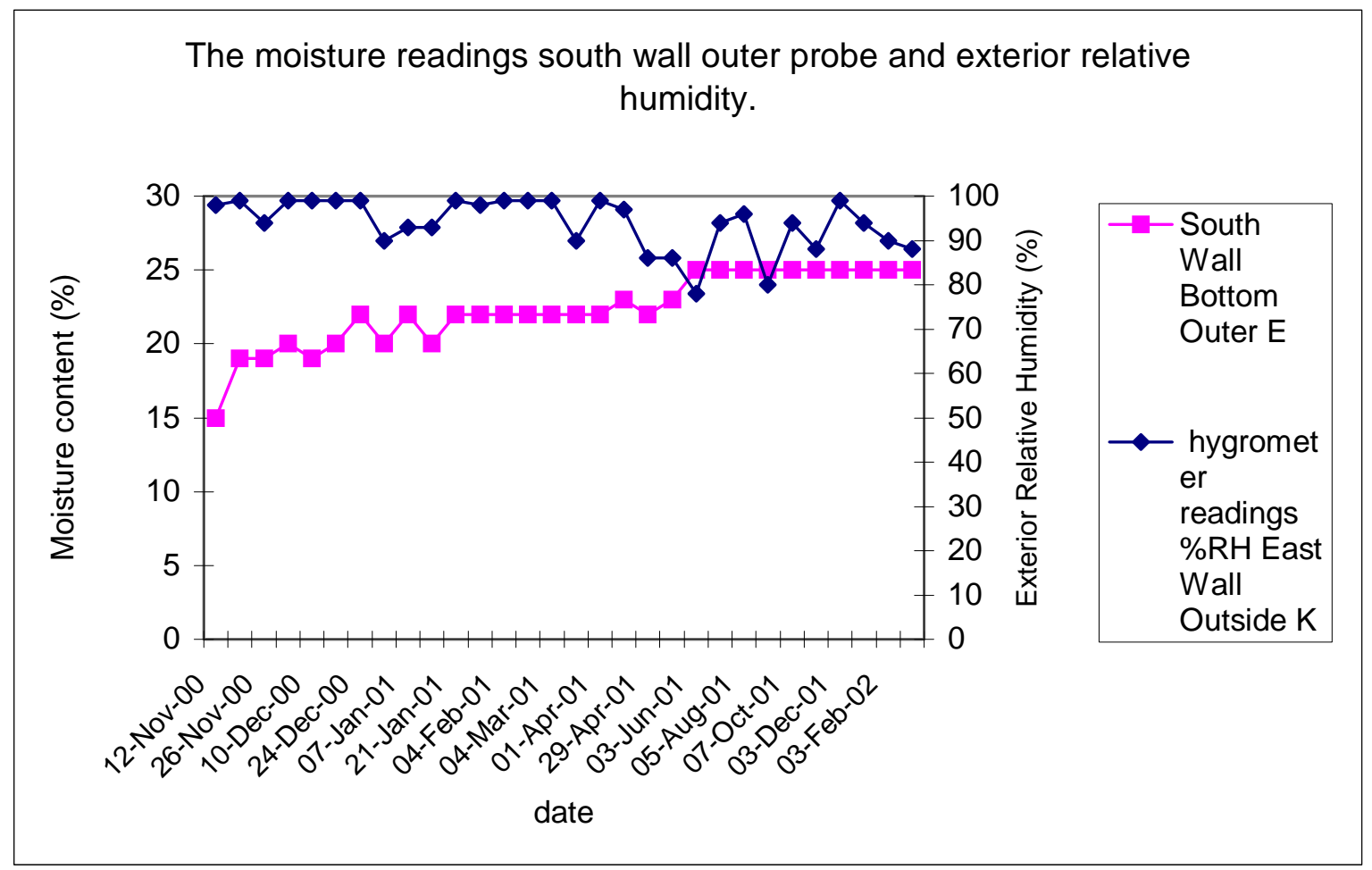

Figure 6, Moisture readings south wall, outer probe and exterior humidity.

The moisture content readings shown in figure 6 are taken from the outer lower probe in the most exposed, southerly wall. It can be seen that as the outside humidity rises, the moisture content of the wall of the drops. This may indicate that there is no connection between the relative humidity of the outside air and the moisture uptake of the lower, outer part of this wall. However, changes in temperature may have a further influence on these moisture values, but this information is not available. 


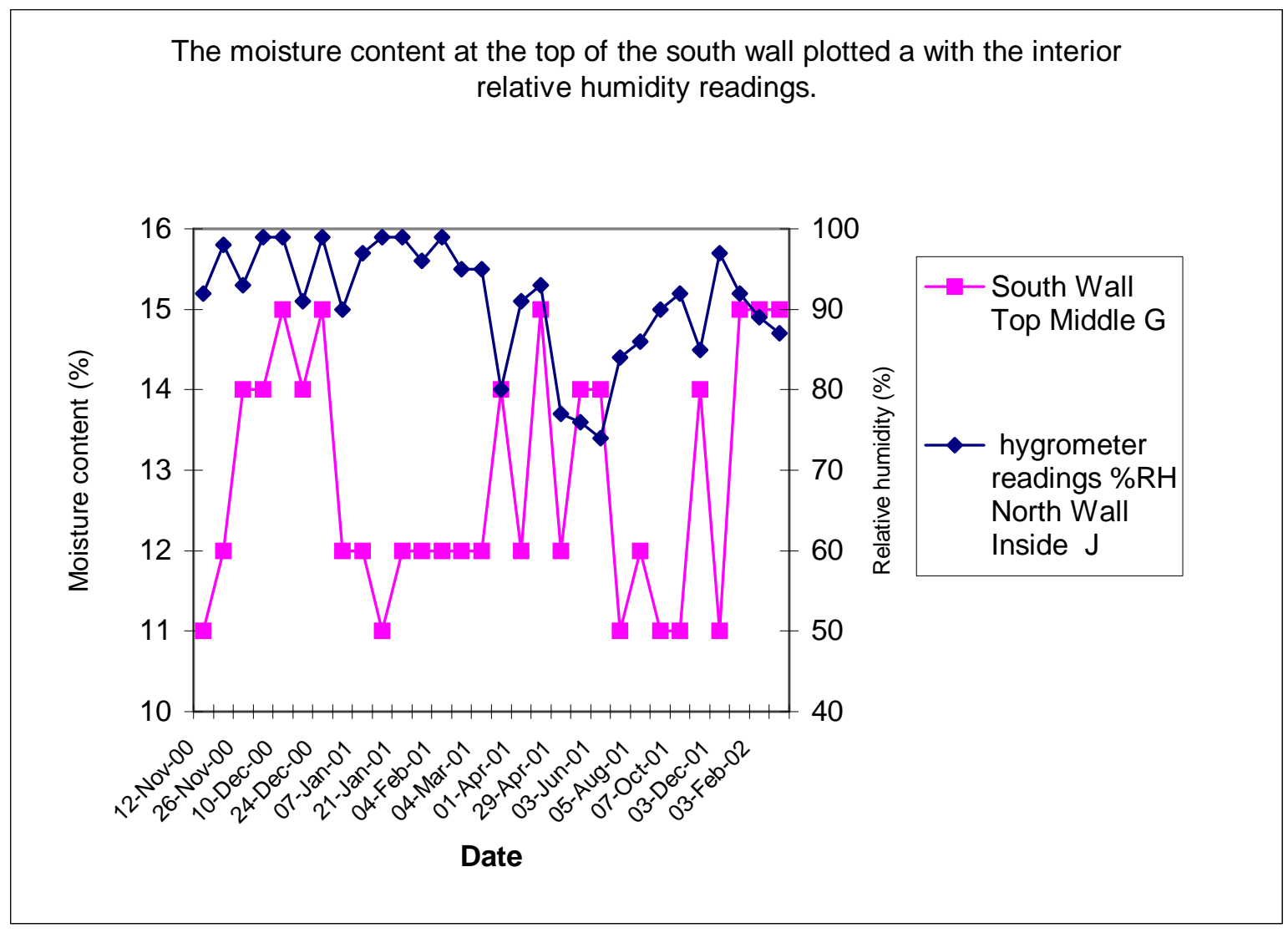

Figure 7, Moisture readings south wall, outer probe and interior humidity

The moisture content readings shown in figure 7 are taken from the middle upper probe in the most exposed, southerly wall. Similar to the readings shown in graph 3 the readings at first appear unconnected, but there maybe the hint of a delayed influence of the interior relative humidity upon the upper, middle part of the south wall. The rise and then dip in the exterior relative humidity readings, peaking at $98 \%$ on the $4^{\text {th }}$ February 2001 and dipping to $75 \%$ at $3^{\text {rd }}$ June 2001 appear to cause a similar peak in wall moisture readings of $15 \%$ at about the $1^{\text {ST }}$ April 2001 and a dip down to $11 \%$ at around the $7^{\text {th }}$ Oct. 


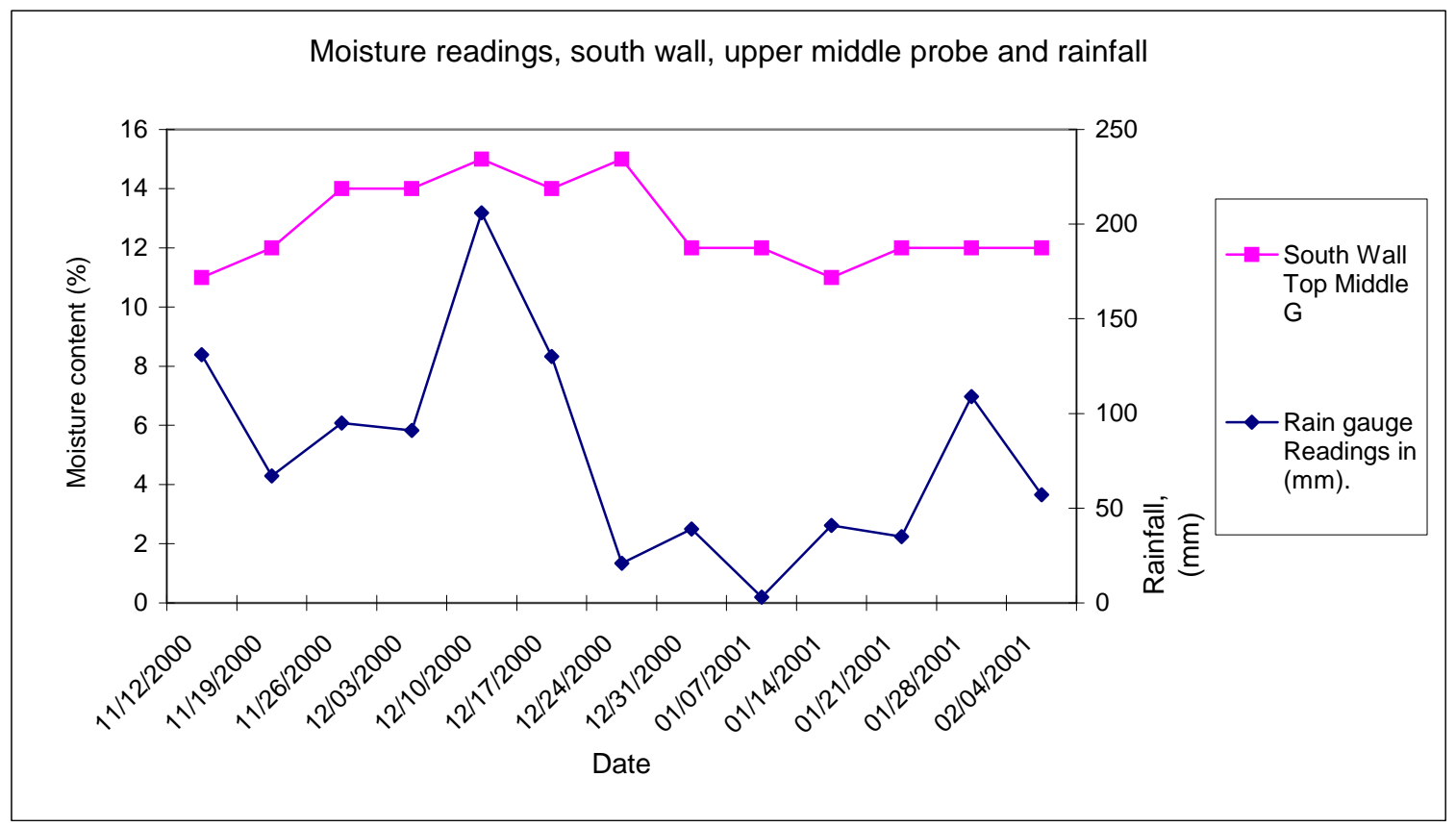

Figure 8, Moisture readings south wall, upper middle probe and rainfall.

Figure 8 shows the measured readings from the top of the southern wall and plots the rainfall measured close by. In December 2000 and to a lesser extent in late January 2001, a peak in the rainfall is reflected in a peak in the wall's moisture content.

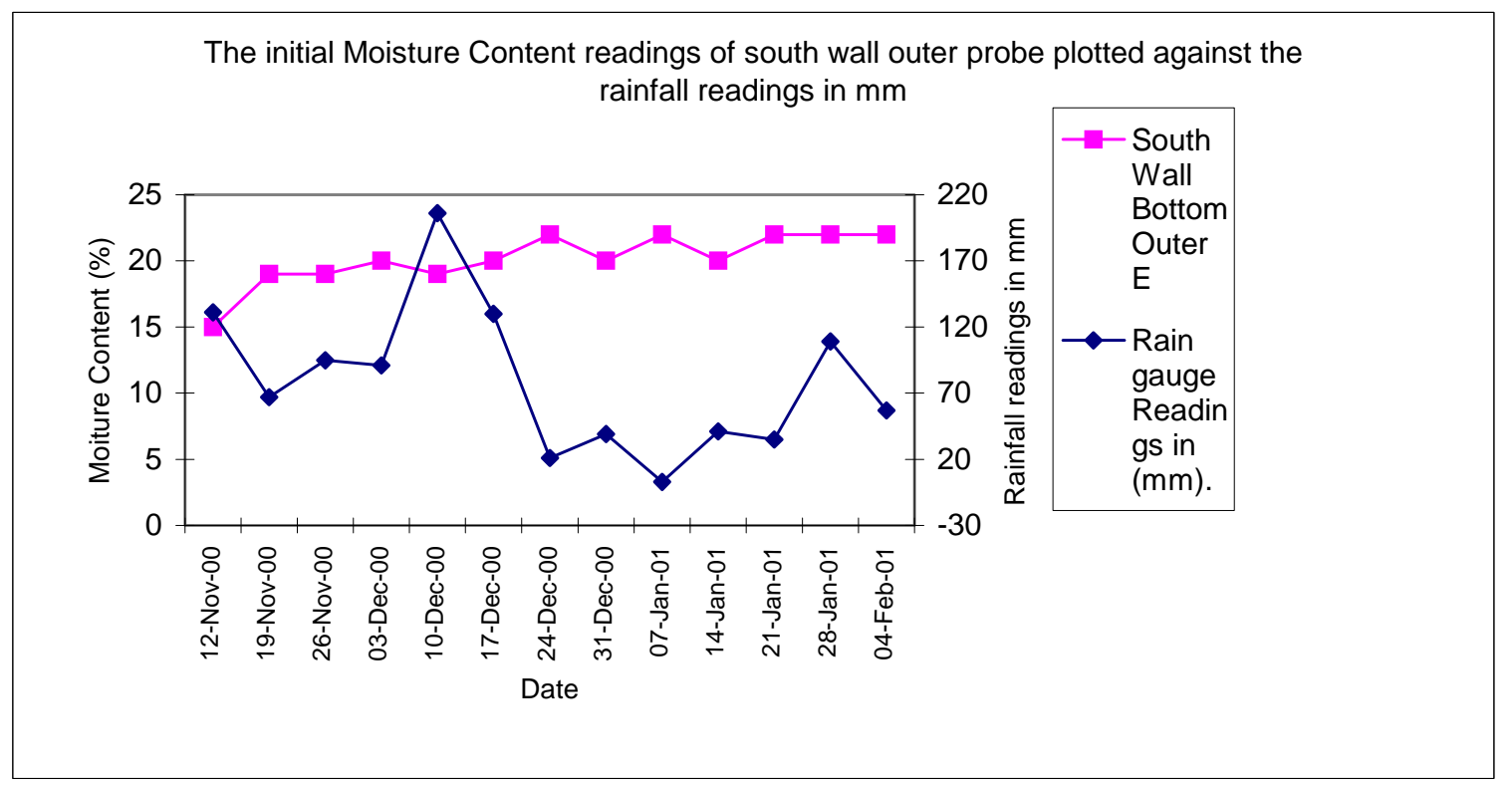

Figure 9, Moisture readings south wall, upper middle probe and rainfall.

Figure 9 shows the measured moisture readings from the lower outer region of the southern wall with the rainfall that was measured close by. The same rainfall peaks shown in figure 7 do not appear to have affected the wall's moisture content. 


\section{Analysis of results of wood-disc sensors placed in the case study building.}

From the results it is evident that there is a higher concentration of moisture in the more exposed south wall in comparison to the more sheltered east and west walls. The continuing increase in the readings from the inner south wall, (particularly during the months of the year when moisture readings from within the bales were expected to drop), were such a cause for concern that the owner of the building decided that the lime render had to be removed and further investigations undertaken. The results of these investigations can be seen in the next section of this paper.

It can also be seen that there is little direct correlation between the variance of exterior and interior relative humidity levels and corresponding variances of the moisture content readings within the bales. However, over longer time periods any theories concerning time lag of moisture movement through straw-bale walls maybe better determined.

A better correlation between the average rainfall close to the building and the moisture content of the upper part of the 'wettest' wall was observed. There was no evidence of water ingress due to faulty render of roofing coverage to suggest that wind-driven penetrating dampness was responsible for this association. The average moisture figures from the probe in the top of the south wall were quite low compared to the readings from the probes at different orientations and lower down and considerably lower than the lower outer probe readings from the same wall. It therefore suggests that the drier the straw-bale wall the more readily it will be to take up moisture associated with rainfall, but not necessarily from water vapour in the surrounding atmosphere.

\section{Measurements undertaken upon samples taken from the straw immediately behind the render of the south-facing wall of the case study building.}

The south wall of the case study building had been rapidly gaining moisture since construction. There were three wood-disc probes in the south wall inserted through the floor into the wall. Probe $\mathrm{G}$ situated at the top of the wall constantly showed a moisture content reading of $15 \%$ and as this was lower than most other readings around the building, gave no cause for concern. Probe $\mathrm{E}$ was situated in the outer section of the south wall and had shown moisture readings in excess of $20 \%$ for some time. Probe $F$ was situated in the inner section of the wall and had a fairly steady moisture content of $15 \%$ moisture content.

It was therefore concluded that the cause of the high moisture reading was moisture penetrating the render on the outside face of the south side of the building. As there were no more probes located lower down the wall it was not possible to locate how far down the wall the moisture reading became higher. However, as the inner probe, placed only $100 \mathrm{~mm}$ from the outer probe had as low a moisture content reading as the probe placed in the top of the wall, it can be assumed that even in quite moist areas of straw, moisture migration is relatively slow. 
It was decided to remove the lower part of the lime render and expose the straw. This has presented a unique opportunity for samples to be taken from around the wood-disc probe that has been in situ for over a year. The lower part of the straw felt damp, this was removed and replaced with fresh straw. The removed samples were oven dried to find the exact moisture content and these values compared with the readings the sensor has been giving for the straw in this location.

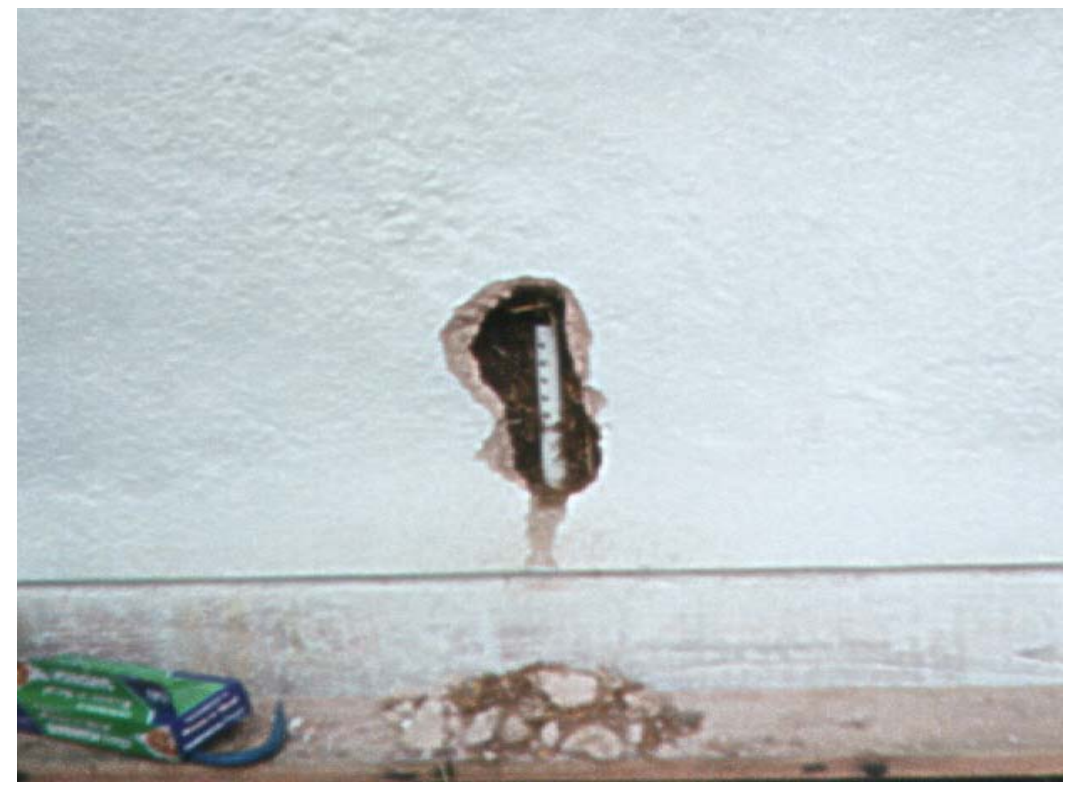

Figure 10, Chipped off render, exposing the probe.

Five samples were oven dried and the average moisture content of the removed damp straw from the south wall was $27 \%$. This value compares well with the $25 \%$ moisture content reading from the wood-disc sensor. The previous laboratory calibration gave a potential accuracy of $+/-1 \%$ between oven drying and wood-disc sensors and this field comparison, with $2 \%$ difference supports this degree of accuracy.

An alternative method to gauge the moisture content of any straw-bale wall was used. Moisture readings from adjacent or representative sheltered exterior timber, using the same resistivity moisture meter used to monitor the wood-disc probes were taken. Graph 7 shows a comparison of the moisture content readings taken from the inner wood-disc sensor of the south wall and sheltered exterior timber. 


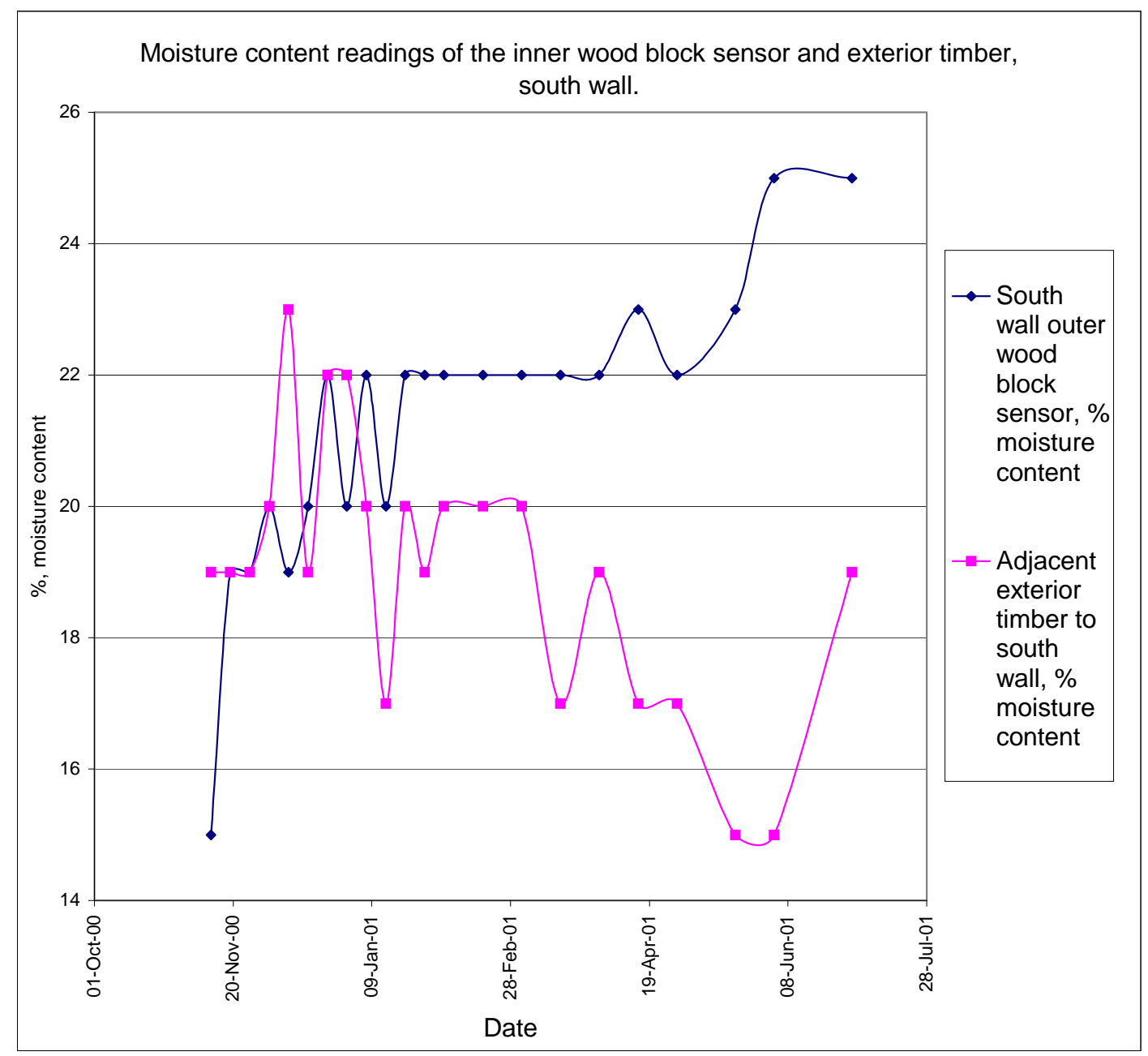

Figure 11, Results of moisture content measurements using the inner wood-disc sensor and exterior adjacent timber in the south wall of the case study building between November 2000 and July 2001.

Figure 11 shows a similarity in the moisture content readings of the straw-bale probe and the exterior timber until the spring of 2001. At this point the exterior timber dries whereas the moisture content of the straw within the wall continues to rise. The divergence is at its greatest in the summer of 2001 when the exterior timber is approximately $8 \%$ drier than the readings from the straw-bale wall. This level of divergence is obviously not a good indicator of the moisture conditions within the strawbale wall. For this reason it is probably only best to use exterior timber reading as an indicator of straw-bale walls moisture content during the winter months and only as a guide.

\section{Conclusions.}

As a form of moisture monitoring, wood-disc sensors proved to be easy to use and reasonably accurate. The wood-disc sensors used in this study to monitor the moisture content of straw-bale walls, although simple and inexpensive allow the user to measure moisture content in straw-bale walls within an accuracy of $+/-2 \%$.

Changes in temperature in a straw-bale used for calibration purposes did not appear to markedly alter the accuracy of the wood-disc sensors over the temperature ranges encountered in the study. However, it was found that an increase in temperature in the 
straw surrounding a wood-disc moisture probe did lead to greater moisture content measurements and this most likely increased the relative humidity within the straw-bale wall.

The results from the analysis of the monitored case study building showed levels of moisture content for 7 of the 8 monitored wood-disc sensors of below $20 \%$. This is at moisture content below the level associated with the start of degradation of the straw. However, a wood-disc sensor placed in one severely exposed wall did record moisture contents of $25 \%$ for a period of months. Once the render covering the lower part of the exposed wall was removed it was confirmed that the straw in this area was degrading. Oven drying of straw samples from around the wood-disc probe confirmed that the probe was reading $2 \%$ below the oven-dried samples. This was felt to further confirm the accuracy and applicability of wood-disc sensors.

Using sheltered external timber adjacent to straw-bale walls as an indicator of strawbale moisture content was found to give a reasonable correlation in winter periods but was inaccurate at other times of the year.

\section{Future Work}

Although this study has confirmed the use of wood-disc sensors as a robust technique for monitoring moisture content of straw-bale walls with a reasonable level of accuracy, many questions still remain.

The moisture performance of straw-bale buildings soon after completion, possibly after wet finishes have been used has yet to be established. How long until any initial moisture that was contained within straw-bales is dissipated? Questions also remain concerning the density and levels of compaction of bales and the effects upon moisture and thermal performance.

The use of hybrid designs of walling, such as the use of light clay buildings, a wet mixture of clay slip and straw, may have long drying times and may have to be left unrendered to allow appropriate drying to take place. A comparison of timber clad and lime rendered straw-bale walls is also planned by the authors.

A fundamental question that has not been addressed in this work is the affects of moisture generated by occupants and activities in a working dwelling built from strawbales. The authors are intending to extend the in-situ moisture monitoring study to include such a dwelling in the near future.

Acknowledgements

The authors are grateful to Helen and Kevin Ireland for their general help and their assistance taking readings. Habib Gonzalez for his advice concerning the design of the wood-disc probe.

\section{References}

1. CIRIA Current Project, The use of agricultural crops (plant and animal) in construction, (RP680). Core Members, DTI, DEFRA, The Eden Project 
2. Christian, J.,. Desjarlais, O., and Stovall, P.E , Straw-bale Wall Hot Box Test Results and Analysis, ASRAE Conf, The Thermal Performance of the Exterior Envelopes of Buildings VII -- 4b103, Florida, December 1998.

3. Steen, A., Steen, B. and Bainbridge, D., The Straw-bale House, Chelsea Green Publishing Company,1994

4. Still, D. Our straw Bale dorm: 2 years later. URL: http:// www.efn.org/ arro/strawbale.htm. 1997

5. Summers, M., Blunk, S. And Jenkins, B., Moisture and thermal conditions for the degradation of rice straw, ASAE Annual International Meeting/CIGR XVth Worold Congress, Chicago, July $28^{\text {th }}$-July $31^{\text {st }}, 2002$.

6. Straub, J and Schumacher, C, Monitoring the hygrothermal performance of Straw bale walls, URL: http://www.ecobuildnetwork.org/strawbale.htm, 2003.

7. Fugler, D., Straw-bale Moisture Research, Canada Mortgage and Housing Corporation, 2000

8. Gonzalez H., Home Made Straw-bale Moisture Meters, The Last Straw, Network productions Inc,Spring, 1998, Issue No: 22, Page No: 31

9. Woolley, T \& Kimmins, S. Green Building Handbook, volume 2. London: E \& FN Spon, 2000.

10. Lacinski, P. and Bergeron,M., Serious Straw-bale, Chelsea Green Publishing Company, 2000. 